Editorial:

\title{
Practice of artificial intelligence in geotechnical engineering
}

\author{
Zhen-yu YIN ${ }^{1}$, Guest Editor-in-Chief \\ Yin-fu JIN ${ }^{1}$, Zhong-qiang LIU ${ }^{2}$, Guest Editors \\ ${ }^{I}$ Department of Civil and Environmental Engineering, The Hong Kong \\ Polytechnic University, Hung Hom, Kowloon, Hong Kong, China \\ ${ }^{2}$ Department of Natural Hazards, Norwegian Geotechnical Institute, \\ Oslo, Norway \\ E-mail: zhenyu.yin@polyu.edu.hk; yinfu.jin9019@gmail.com; \\ zhongqiang.liu@ngi.no
}

https://doi.org/10.1631/jzus.A20AIGE1

Geotechnical engineering deals with materials (e.g. soil and rock) that, by their very nature, exhibit varied and uncertain behavior due to the imprecise physical processes associated with their formation (Mitchell and Soga, 2005). Modeling the behavior of such materials in geotechnical engineering applications is complex and sometimes beyond the ability of most traditional forms of physically-based engineering methods. In recent years, the application of artificial intelligence (AI) in a wide range of geotechnical engineering has grown rapidly (Nawari et al., 1999; Miranda, 2007; Javadi and Rezania, 2009; Shahin, 2013, 2016; Chen et al., 2018; Yin et al., 2018; Jin et al., 2019a, 2019b, 2019c; Zhang P et al., 2020a). AI can be very useful in solving problems where deterministic solutions are not available or are excessively expensive in terms of computational cost but for which there are significant observations and data available (Turk et al., 2001; Man and Furukawa, 2011; Rashidian and Hassanlourad, 2013; Makantasis et al., 2015; Pirnia et al., 2018; Wang and Sun, 2018; Wang et al., 2019; Yang et al., 2019; Gao et al., 2020). Due to the nature of materials, geotechnical engineering deals with more uncertainties than other fields of civil and mechanical engineering. There is also much monitoring and site investigation data in

\footnotetext{
(D) ORCID: Zhen-yu YIN, https://orcid.org/0000-0003-4154-7304 (C) Zhejiang University and Springer-Verlag GmbH Germany, part of Springer Nature 2020
}

geotechnical engineering which needs to be taken advantage of by using data analytic methods (Goh et al., 1995; Jan et al., 2002; Kung et al., 2007; Rechea et al., 2008; Hashash et al., 2010, 2011; Lü et al., 2012; Huang et al., 2014; Chen et al., 2018; van Boven et al., 2018; Chen et al., 2019a, 2019b; Jin et al., 2019a; Zhang, 2019; Zhang P et al., 2019, 2020a, 2020b). Therefore, AI can be a suitable and effective alternative route to solving geotechnical engineering problems and significant developments have been made in recent years as much attention has been given to the area. Unfortunately, there has been no dedicated special issue or workshop devoted to it.

This special issue contains original and hitherto unpublished works on the applications of AI in geotechnical engineering. Focal points of the issue include, but are not limited to, innovative applications of: (1) Metaheuristics and their applications in intelligent automation and global optimization including evolutionary algorithms, swarm intelligence, natural and biologically inspired metaheuristics; (2) Traditional machine learning (ML) methods, such as artificial neural networks (ANNs), genetic programming (GP), evolutionary polynomial regression (EPR), support vector machines (SVMs), and random forest (RF); (3) Deep learning and real world applications, such as deep neural networks (DNNs), convolutional neural network $(\mathrm{CNN})$, and recurrent neural networks (RNNs); (4) Aspects of software engineering, e.g. intelligent programming environments, verification and validation of AI-based software, software and hardware architectures for the real-time use of AI techniques, safety, and reliability; (5) Big data analytics; (6) Industrial experience in the application of the above techniques, e.g. case studies or benchmarking exercises.

Thus, we invited prestigious scientists in the field to share their expertise and perspectives. The collected papers cover the various topics mentioned, such as application of long short term memory 
(LSTM) neural network, gated recurrent unit (GRU), and RF to different kinds of geotechnical problems.

Zhang DM et al. (2020) developed a nonparametric ensemble AI approach to calculating the compression modulus $\left(E_{\mathrm{s}}\right)$ of soft clay in contrast to the traditional regression models proposed in previous studies. A gradient boosted regression tree (GBRT) algorithm was used to discern the non-linear pattern between input variables and the target response, while a genetic algorithm (GA) was adopted for tuning the GBRT model's hyper-parameters. The model was tested through 10 -fold cross validation. A dataset of 221 samples from 65 engineering survey reports from Shanghai infrastructure projects was constructed to evaluate the accuracy of the new model's predictions. A comparison of the performance of empirical formulas and the proposed ML method for predicting foundation settlement indicated the rationality of the proposed ML model and its applicability to the compressive deformation of geotechnical systems, solved by retraining the model using local data. This research provides a useful reference for future multi-parameter prediction of soil behavior.

Lu et al. (2020) applied the LSTM deep-learning technique to calculate the shaft resistance of cast-insite piles. The proposed method allowed accurate estimation of the shaft resistance of cast-in-site piles, not only under the ultimate load but also under the working load. Comparisons with empirical methods confirmed the effectiveness of the proposed method for the shaft-resistance estimation of cast-in-site piles on reclaimed ground in offshore areas.

Cheng et al. (2020) employed GP to obtain a simplified statistical model for formulating the relationship between field-monitored soil suction in drying cycles. They selected five influencing parameters, initial suction, relative humidity, drying time, the ratio of the distance from the tree to the tree canopy radius, and the depth from the ground surface. The data used for model development was collected from a field monitoring test in the campus of the University of Macau, China. The results indicated that the model gives a reasonable estimation for the spatiotemporal variations of soil suction near a tree with acceptable errors.

Godoy et al. (2020) applied ML methods, such as logistic regression, Naive Bayes, and hidden
Markov models, to classify quick and highly sensitive clays in two sites in Norway based on normalized cone penetration tests with pore water pressure measurement (CPTu). The results showed an important increase in the classification accuracy even with small training sets.

Sun et al. (2020) presented two examples to demonstrate the capability and accuracy of the probabilistic estimation method proposed in their previous study (Yang et al., 2019) to characterize soil spatial variability with displacement responses. The first example was a soil slope subject to a surcharge load, in which the spatially varied field of the elastic modulus is estimated with displacements. The results showed that estimations based on horizontal displacements were more accurate than those based on vertical displacements. The accuracy of the estimated field was substantially reduced by increasing the variance of elastic modulus. However, the estimation was generally acceptable as the error was not more than $10 \%$, even for the high variance case $\left(\mathrm{COV}_{E}\right.$ $=1.5$ ). The accuracy of estimation was also affected by the type of covariance function and the correlation length. When the correlation length decreased, the accuracy of estimation was reduced. The second example was a validation of laboratory model tests where a horizontal load was applied on a layered ground. The estimated thicknesses of soil layers were close to those in the real situation, which demonstrates the capacity of the estimation method.

Liu et al. (2020) adopted the LSTM neural network, the RF algorithm, and the GRU algorithm to predict landslide displacement in the Three Gorges Dam reservoir. Three different landslides, each with step-wise displacement characteristics, were modelled with each of the ML algorithms. The prediction by each ML algorithm was validated with observations over a one-year period of three colluvial landslides in the Three Gorges Dam reservoir. The analysis results of the three landslides demonstrated that "deep learning" ML approaches were well suited to predicting landslide displacements. The LSTM and GRU algorithms gave the most encouraging results and can be recommended for prediction of the displacement of step-wise type colluvial landslides in the Three Gorges Dam reservoir. Such reliable predictive models should gradually become a component when implementing early warning systems and reducing landslide risk. 
We believe this special issue has provided a special viewpoint for researchers and engineers to present and discuss the recent developments of $\mathrm{AI}$ in geotechnical engineering. The interdisciplinary between machine learning and geotechnics was well highlighted and expressed by the selected publications. We sincerely hope the new algorithms and advanced methodologies shared in this special issue will improve the understanding of AI technologies and strategies, promote the application of new technologies in the field of geotechnical engineering, and quickly realize the intelligent development of geotechnical engineering. We expect the selected articles will arouse the discussion of the majority of scientific researchers, and also hope to bring new inspiration to readers of this journal.

\section{Contributors}

Zhen-yu YIN provided the concept and edited the draft of manuscript. Yin-fu JIN conducted the literature review and wrote the first draft of the manuscript. Zhong-qiang LIU edited the draft of manuscript.

\section{Conflict of interest}

Zhen-yu YIN, Yin-fu JIN, and Zhong-qiang LIU declare that they have no conflict of interest.

\section{References}

Chen RP, Lin XT, Kang X, et al., 2018. Deformation and stress characteristics of existing twin tunnels induced by close-distance EPBS under-crossing. Tunnelling and Underground Space Technology, 82:468-481. https://doi.org/10.1016/j.tust.2018.08.059

Chen RP, Zhang P, Kang X, et al., 2019a. Prediction of maximum surface settlement caused by earth pressure balance (EPB) shield tunneling with ANN methods. Soils and Foundations, 59(2):284-295. https://doi.org/10.1016/j.sandf.2018.11.005

Chen RP, Zhang P, Wu HN, et al., 2019b. Prediction of shield tunneling-induced ground settlement using machine learning techniques. Frontiers of Structural and Civil Engineering, 13(6):1363-1378. https://doi.org/10.1007/s11709-019-0561-3

Cheng ZL, Zhou WH, Ding Z, et al., 2020. Estimation of spatiotemporal response of rooted soil using a machine learning approach. Journal of Zhejiang UniversitySCIENCE A (Applied Physics \& Engineering), 21(6): 462-477. https://doi.org/10.1631/jzus.A1900555

Gao MY, Zhang N, Shen SL, et al., 2020. Real-time dynamic earth-pressure regulation model for shield tunneling by integrating GRU deep learning method with GA optimization. IEEE Access, 8:64310-64323.
https://doi.org/10.1109/ACCESS.2020.2984515

Godoy C, Depina I, Thakur V, 2020. Application of machine learning to the identification of quick and highly sensitive clays from cone penetration tests. Journal of Zhejiang University-SCIENCE A (Applied Physics \& Engineering), 21(6):445-461. https://doi.org/10.1631/jzus.A1900556

Goh ATC, Wong KS, Broms BB, 1995. Estimation of lateral wall movements in braced excavations using neural networks. Canadian Geotechnical Journal, 32(6):59-64. https://doi.org/10.1139/t95-103

Hashash YMA, Levasseur S, Osouli A, et al., 2010. Comparison of two inverse analysis techniques for learning deep excavation response. Computers and Geotechnics, 37(3): 323-333. https://doi.org/10.1016/j.compgeo.2009.11.005

Hashash YMA, Song H, Osouli A, 2011. Three-dimensional inverse analyses of a deep excavation in Chicago clays. International Journal for Numerical and Analytical Methods in Geomechanics, 35(9):1059-1075. https://doi.org/10.1002/nag.949

Huang ZH, Zhang LL, Cheng SY, et al., 2014. Back-analysis and parameter identification for deep excavation based on Pareto multiobjective optimization. Journal of Aerospace Engineering, 28(6):A4014007. https://doi.org/10.1061/(ASCE)AS.1943-5525.0000464

Jan JC, Hung SL, Chi SY, et al., 2002. Neural network forecast model in deep excavation. Journal of Computing in Civil Engineering, 16(1):59-65. https://doi.org/10.1061/(asce)0887-3801(2002)16:1(59)

Javadi A, Rezania M, 2009. Applications of artificial intelligence and data mining techniques in soil modeling. $\mathrm{Ge}$ omechanics and Engineering, 1(1):53-74. https://doi.org/10.12989/gae.2009.1.1.053

Jin YF, Yin ZY, Zhou WH, et al., 2019a. Identifying parameters of advanced soil models using an enhanced transitional Markov chain Monte Carlo method. Acta Geotechnica, 14(6):1925-1947. https://doi.org/10.1007/s11440-019-00847-1

Jin YF, Yin ZY, Zhou WH, et al., 2019b. Multi-objective optimization-based updating of predictions during excavation. Engineering Applications of Artificial Intelligence, 78:102-123. https://doi.org/10.1016/j.engappai.2018.11.002

Jin YF, Yin ZY, Zhou WH, et al., 2019c. A single-objective EPR based model for creep index of soft clays considering $\mathrm{L}_{2}$ regularization. Engineering Geology, 248:242255. https://doi.org/10.1016/j.enggeo.2018.12.006

Kung GTC, Hsiao ECL, Schuster M, et al., 2007. A neural network approach to estimating deflection of diaphragm walls caused by excavation in clays. Computers and Geotechnics, 34(5):385-396. https://doi.org/10.1016/j.compgeo.2007.05.007

Liu ZQ, Guo D, Lacasse S, et al., 2020. Algorithms for intelligent prediction of landslide displacements. Journal of 
Zhejiang University-SCIENCE A (Applied Physics \& Engineering), 21(6):412-429. https://doi.org/10.1631/jzus.A2000005

Lu SL, Zhang N, Shen SL, et al., 2020. A deep-learning method for evaluating shaft resistance of the cast-in-site pile on reclaimed ground using field data. Journal of Zhejiang University-SCIENCE A (Applied Physics \& Engineering), 21(6):496-508. https://doi.org/10.1631/jzus.A1900544

Lü Q, Chan CL, Low BK, 2012. Probabilistic evaluation of ground-support interaction for deep rock excavation using artificial neural network and uniform design. Tunnelling and Underground Space Technology, 32:1-18. https://doi.org/10.1016/j.tust.2012.04.014

Makantasis K, Protopapadakis E, Doulamis A, et al., 2015. Deep convolutional neural networks for efficient vision based tunnel inspection. IEEE International Conference on Intelligent Computer Communication and Processing, p.335-342. https://doi.org/10.1109/ICCP.2015.7312681

Man H, Furukawa T, 2011. Neural network constitutive modelling for non-linear characterization of anisotropic materials. International Journal for Numerical Methods in Engineering, 85(8):939-957. https://doi.org/10.1002/nme.2999

Miranda TFS, 2007. Geomechanical Parameters Evaluation in Underground Structures: Artificial Intelligence, Bayesian Probabilities and Inverse Methods. PhD Thesis, University of Minho, Guimarães, Portugal, p.291.

Mitchell JK, Soga K, 2005. Fundamentals of Soil Behavior, 3rd Edition. Wiley, Hoboken, USA.

Nawari NO, Liang R, Nusairat J, 1999. Artificial intelligence techniques for the design and analysis of deep foundations. Electronic Journal of Geotechnical Engineering, 4:1-21.

Pirnia P, Duhaime F, Manashti J, 2018. Machine learning algorithms for applications in geotechnical engineering. GeoEdmonton 2018.

Rashidian V, Hassanlourad M, 2013. Application of an artificial neural network for modeling the mechanical behavior of carbonate soils. International Journal of Geomechanics, 14(1):142-150. https://doi.org/10.1061/(ASCE)GM.1943-5622.0000299

Rechea C, Levasseur S, Finno R, 2008. Inverse analysis techniques for parameter identification in simulation of excavation support systems. Computers and Geotechnics, 35(3):331-345. https://doi.org/10.1016/j.compgeo.2007.08.008

Shahin MA, 2013. Artificial intelligence in geotechnical engineering: applications, modeling aspects, and future directions. In: Yang XS (Ed.), Metaheuristics in Water, Geotechnical and Transport Engineering. Elsevier, Amsterdam, the Netherland, p.169-204. https://doi.org/10.1016/B978-0-12-398296-4.00008-8

Shahin MA, 2016. State-of-the-art review of some artificial intelligence applications in pile foundations. Geoscience
Frontiers, 7(1):33-44.

https://doi.org/10.1016/j.gsf.2014.10.002

Sun YX, Zhang LL, Yang HQ, et al., 2020. Characterization of spatial variability with observed responses: application of displacement back estimation. Journal of Zhejiang University-SCIENCE A (Applied Physics \& Engineering), 21(6):478-495. https://doi.org/10.1631/jzus.A1900558

Turk G, Logar J, Majes B, 2001. Modelling soil behaviour in uniaxial strain conditions by neural networks. Advances in Engineering Software, 32(10-11):805-812. https://doi.org/10.1016/S0965-9978(01)00032-1

van Boven B, van der Putten P, Åström A, et al., 2018. Real-time excavation detection at construction sites using deep learning. Proceedings of the 17th International Symposium on Intelligent Data Analysis, p.340-352. https://doi.org/10.1007/978-3-030-01768-2_28

Wang K, Sun WC, 2018. A multiscale multi-permeability poroplasticity model linked by recursive homogenizations and deep learning. Computer Methods in Applied Mechanics and Engineering, 334:337-380. https://doi.org/10.1016/j.cma.2018.01.036

Wang K, Sun WC, Du Q, 2019. A cooperative game for automated learning of elasto-plasticity knowledge graphs and models with AI-guided experimentation. Computational Mechanics, 64(2):467-499. https://doi.org/10.1007/s00466-019-01723-1

Yang BB, Yin KL, Lacasse S, et al., 2019. Time series analysis and long short-term memory neural network to predict landslide displacement. Landslides, 16(4):677-694. https://doi.org/10.1007/s10346-018-01127-x

Yin ZY, Jin YF, Shen JS, et al., 2018. Optimization techniques for identifying soil parameters in geotechnical engineering: comparative study and enhancement. International Journal for Numerical and Analytical Methods in Geomechanics, 42(1):70-94. https://doi.org/10.1002/nag.2714

Zhang DM, Zhang JZ, Huang HW, et al., 2020. Machine learning-based prediction of soil compression modulus with application of 1D settlement. Journal of Zhejiang University-SCIENCE A (Applied Physics \& Engineering), 21(6):430-444. https://doi.org/10.1631/jzus.A1900515

Zhang P, 2019. A novel feature selection method based on global sensitivity analysis with application in machine learning-based prediction model. Applied Soft Computing, $85: 105859$. https://doi.org/10.1016/j.asoc.2019.105859

Zhang P, Chen RP, Wu HN, 2019. Real-time analysis and regulation of EPB shield steering using random forest. Automation in Construction, 106:102860. https://doi.org/10.1016/j.autcon.2019.102860

Zhang P, Yin ZY, Jin YF, et al., 2020a. A novel hybrid surrogate intelligent model for creep index prediction based on particle swarm optimization and random forest. Engineering Geology, 265:105328. 
https://doi.org/10.1016/j.enggeo.2019.105328

Zhang P, Chen RP, Wu HN, et al., 2020b. Ground settlement induced by tunneling crossing interface of water-bearing mixed ground: a lesson from Changsha, China. Tunnelling and Underground Space Technology, 96:103224. https://doi.org/10.1016/j.tust.2019.103224

\section{中文概要}

题 目: 人工智能在岩土工程中的实践

概 要：岩土材料的复杂和不确定性致使传统理论在模拟 和预测岩土工程问题经常显得无能为力。近年
来, 随着人工智能和大数据技术的快速发展, 人 工智能技术在岩土工程领域有了广泛应用, 例如 岩土参数的优化智能识别和预测、边坡变形的长 期预测、基坑开挖过程变形的实时监测和预测以 及盾构隧道的变形和盾构机刀盘参数的预测和 更新等。为此, 本专辑收集了在该研究领域具有 代表性的研究成果, 介绍了人工智能技术在岩土 工程领域的进展和未来发展潜力, 希望能帮助读 者快速了解人工智能技术在岩土工程中的应用, 以及推动岩土工程的智能化发展, 为实现岩土工 程智能化提供科学依据和技术支撑。

关键词: 人工智能; 岩土工程; 大数据

\section{Introducing Guest Editor-in-Chief and Guest Editors:}

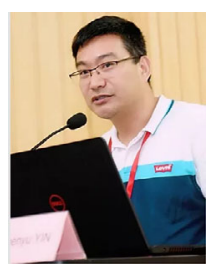

\section{Guest Editor-in-Chief}

Dr. Zhen-yu YIN has been an Editorial Board Member of Journal of Zhejiang University-SCIENCE A (Applied Physics \& Engineering) since 2019.

Dr. Zhen-yu YIN has been an Associate Professor of Geotechnical Engineering at The Hong Kong Polytechnic University, China since 2018. Dr. YIN received his BEng in Civil Engineering from Zhejiang University in 1997, followed by a 5-year engineering consultancy at the Zhejiang Jiahua Architecture Design Institute. Then, he obtained his MSc and PhD in Geotechnical Engineering at Ecole Centrale de Nantes (France) in 2003 and 2006, respectively. Dr. YIN has been working as a postdoctoral researcher at Helsinki University of Technology (Finland), the University of Strathclyde (UK), Ecole Centrale de Nantes, and the University of Massachusetts (USA). In 2010, he joined Shanghai Jiao Tong University as a Special Researcher and received "Professor of Exceptional Rank of Shanghai Dong-Fang Scholar." In 2013, he joined Ecole Centrale de Nantes as Associate Professor before moving to Hong Kong. Dr. YIN has published over 150 articles in peer reviewed international journals with an $H$-index of Web of Science of 33. Since 2012, he has been a member of the Granular Materials Committee of the American Society of Civil Engineers.

\section{Guest Editors}

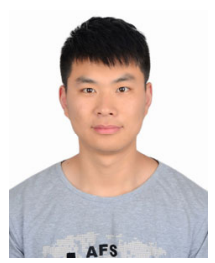

Dr. Yin-fu JIN

Department of Civil and Environmental Engineering, The Hong Kong Polytechnic University, Hung Hom, Kowloon, Hong Kong, China

E-mail: yinfu.jin9019@gmail.com

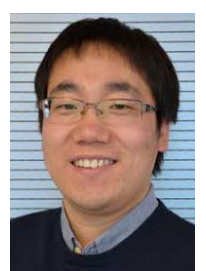

Dr. Zhong-qiang LIU, Senior Engineer Department of Natural Hazards, Norwegian Geotechnical Institute, Oslo, Norway E-mail: zhongqiang.liu@ngi.no 